\title{
Repensando a Rede de Saúde Mental do Território a Partir da Implantação do NASF
}

\author{
Frederico, Deison Fernando; Mendes, Luiza da Costa \\ Mestrado em Saúde Coletiva Universidade Federal Fluminense e SMS/Rj — deisonf@hotmail.com
}

O Núcleo de Apoio à saúde da família na zona norte do Rio de Janeiro, se consolida nesta área em Novembro de 2011. Os profissionais do NASF detectaram uma fragilidade da rede que além de dispor de poucos dispositivos se encontravam pouco articulados. o trabalho principalmente no campo da saúde mental, num primeiro momento residiu em construir um fluxo entre os serviços fomentando um diálogo possível para o compartilhamento de casos que necessitam de ações intersetoriais. na vivência cotidiana se percebeu a necessidade de trabalhar essa rede, que servirá de suporte para as equipes permitindo a efetivação do matriciamento num plano mais objetivo. Percebemos o gargalo que tem se formado na saúde mental nesta região, devido a uma superlotação dos Ambulatórios e a precarização da atenção psicossocial. o NASF vem instigar a discussão de um cuidado em saúde mental possível na atenção básica como preconizado pela Reforma Psiquiátrica, uma vez que o usuário se encontra na interseção dos serviços, podendo ele pertencer ao mesmo tempo a todos os níveis de atenção à Saúde. o apoio da equipe especializada na atenção primária vem potencializar as possibilidades de intervenções dos serviços de média e alta complexidade, uma vez que a estratégia se propõe a exercer um cuidado longitudinal e in loco. um dos resultados observados do trabalho em rede desenvolvido pelo NASF é a diminuição dos encaminhamentos efetuados pela ESF, tendo que estes tem ocorrido de forma responsável e qualificada.

Frederico, Deison Fernando; Mendes, Luiza da Costa. Repensando a Rede de Saúde Mental do Território a Partir da Implantação do Nasf. In: Anais do Congresso Internacional de Humanidades \& Humanização em Saúde [= Blucher Medical Proceedings, num.2, vol.1]. São Paulo: Editora Blucher, 2014. ISSN $2357-7282$ DOI 10.5151/medpro-cihhs-10456 